\title{
The Impact of Brexit on the City of London
}

By Sir Mark Boleat, Former Policy Chairman, City of London Corporation

Brexit will have profound effects on the financial services industry in the UK, commonly although somewhat misleadingly referred to as "the City of London". What those effects will be, will not be known for many years, largely because the nature of the future relationship between Britain and the EU is not yet known and may well not be known for some time. And even when it is known it will take some years for the market to fully adjust, at a time when many other factors will also be influencing the evolution of financial service markets.

However, Brexit has already had a significant impact, although most of this impact is not easy to see. Even though Britain will be outside the EU it will be affected by EU policies. In particular, those financial institutions that wish to operate within the EEA post-Brexit will have to comply with EU rules. It follows that being able to influence those rules is important, particularly as Britain dominates the European wholesale financial markets. The UK has been very successful at influencing EU regulation over the last 30 years through a combination of expertise that goes with the size and importance of the industry, excellent work by officials in the Treasury and regulatory bodies, good input from the industry by individual companies and trade associations, and excellent work by a small number of Members of the European Parliament.

Immediately after the Referendum this influence diminished as there is less capacity, and indeed willingness, for Britain to have an influence and give British views the same weight as they previously had.

A second factor has been the diversion of resources away from strategy and business development to dealing with Brexit. Large project teams have been put in place in major companies, aided by consultancy and legal support. So, staff who were previously working on expanding the business are now working on protecting existing business. This will not show through in aggregate figures but will be 
apparent in profit and loss accounts. Major banks have individually spent over $£ 100$ million on Brexit plans and the cumulative costs runs into billions - the Boston Consulting Group has estimated the total restructuring cost for banks at $£ 15$ billion.

It is very likely that new investment has been reduced, though it is almost impossible to give precise examples. Decisions that might have been to expand or to set up in Britain were deferred or even cancelled. Equally, as outlined in the previous section, businesses have been building up their operations in other EEA centres in anticipation of Brexit. All these decisions have been at the margin, perhaps affecting anything between a few jobs and 100 jobs at a time, but cumulatively they are significant.

Accordingly, the effect on employment so far has been comparatively small, and largely reflects new jobs not being created. For the most part the new offices in the EU-27 are employing additional staff locally rather than taking staff from London and other parts of the UK. Estimates of "jobs lost" prior to "Brexit day" are in the 5,000 -10,000 range.

The negotiations currently taking place between Britain and the EU are now largely irrelevant to the short-term position - except in respect of protecting existing insurance and derivative contracts. Financial services business cannot gamble. They have to assume a worst-case scenario, which is that Britain will leave the EU on 29 March 2019 with no deal. To be able to continue providing services to their clients those institutions that rely on passporting will already have taken all the necessary steps to relocate functions to the EU 27, a process that can take between months and years. Should a transitional arrangement be agreed then the functions will be transferred in a more orderly way, with longer periods for testing and securing the necessary staff and other resources, but the relocation decisions will not change.

The longer-term impact of Brexit on the financial services industry will depend primarily on the final exit agreement between Britain and the EU. The alternative scenarios were analysed in a report by the Oliver Wyman consultancy (Oliver Wyman, 2017). It concluded that if the UK retained market access on near to current terms the impact would be only modest, with 3,000-4,000 jobs at risk and tax revenue falling by 
less $£ 500$ million a year. At the other end of the spectrum, if the UK had no special status with the EU - now the most likely option - the industry would lose $£ 18-20$ billion a year in revenue, which would put $31,000-35,000$ jobs at risk along with £3-5 billion a year of tax revenue. There would also be a knock-on impact on the ecosystem that could result in the loss from the UK of activities that operate alongside those parts of the business that leave, the shifting of entire business units, or the closure of lines of business due to increased costs. An estimated further £14-18 billion of revenue, 34,000-40,000 jobs and £5 billion in tax revenue per annum might be at risk. So, the worst-case scenario - which currently looks the most likely is the loss of 75,000 jobs and $£ 10$ billion of tax revenue.

The current British government position is that Britain will have no special status so the worst-case scenario is the most likely, but it will play out over a period of years. The only way that this can be avoided is for Britain to stay in the European Economic Area permanently. For this to happen would require some political summersaults. 